\title{
Engineering Design of a Voloxidizer with a Double Reactor for the Hull Separation of Spent Nuclear Fuel Rods
}

\author{
Young-Hwan Kim, Yung-Zun Cho, Jae-Won Lee, Ju-Hoo Lee, \\ Sang-Chae Jeon, and Do-Hee Ahn \\ Korea Atomic Energy Research Institute, Daedeok-daero 989-111, Yuseong-gu, Daejeon 305-353, Republic of Korea \\ Correspondence should be addressed to Young-Hwan Kim; yhkim3@kaeri.re.kr
}

Received 26 April 2017; Accepted 28 September 2017; Published 3 December 2017

Academic Editor: Eugenijus Ušpuras

Copyright (c) 2017 Young-Hwan Kim et al. This is an open access article distributed under the Creative Commons Attribution License, which permits unrestricted use, distribution, and reproduction in any medium, provided the original work is properly cited.

A voloxidizer with a double reactor capable of processing several tens of kilograms of HM/batch of nuclear spent fuel has been developed for the decladding and voloxidation of rod-cuts into hulls and pellets through the conversion of $\mathrm{UO}_{2}$ pellets to $\mathrm{U}_{3} \mathrm{O}_{8}$ powder. In this study, we optimized the engineering design of this voloxidizer to improve its hull-recovery ratio. First, we tested the oxidation performance of the device prototype and evaluated the effectiveness of various mechanical and chemical voloxidizing methods. On the basis of the results, we selected the screw-and-rotation method for the double rotary drum. Next, we derived a theoretical equation for calculating the optimal reactor volume for various rod-cut weights and lengths and then validated the equation using centimeter-scale acryl reactors and hulls. Subsequently, we modularized the main components such as the heater, utility, motor, reactor, valve, and structure. The double reactor was subject to preliminary separation tests of hulls and powder. Moreover, the hull-separation performance of the voloxidizer reactor was tested at a loading of $50 \mathrm{~kg} \mathrm{HM} / \mathrm{batch}$. Finally, the remote assembling and disassembling possibility of the modules were experimentally optimized.

\section{Introduction}

Spent fuel is an unavoidable and highly radioactive byproduct of electricity generation using nuclear power reactors. Nevertheless, it can be an asset if it is effectively recycled. As spent fuel accumulates in Korea, the development of reliable and effective methods for the management of spent fuel has become a priority for the Korea Atomic Energy Research Institute (KAERI). Accordingly, considerable efforts are being devoted to developing a management technology that can enhance the environmental friendliness proliferation resistance and use of the available energy resources [1, 2]. KAERI has been developing pyroprocessing since 1997. Pyroprocessing consists of head-end processes, electrochemical processes, and waste treatment processes. Pyroprocessing has advantages over aqueous process such as less proliferation risk, treatment of spent fuel with relatively high heat and radioactivity, and compact equipment. The purpose of pyroprocessing is to test the process in terms of unit process performance, remote operation of equipment, integration of unit processes, scale-up of the process, and miniaturization of equipment. Also, the rotary voloxidizer in head-end process is required to obtain the very high decladding efficiency [3]. Additionally, KAERI is developing a mechanical head-end process for pyroprocessing, which entails the disassembling, rod-extraction, rod-cutting, voloxidation, and compaction of the spent fuel assembly. Furthermore, voloxidizing equipment capable of processing several tens of kilograms of $\mathrm{HM} /$ batch is being developed to supply $\mathrm{U}_{3} \mathrm{O}_{8}$ powder for the compaction process.

To enhance the hulls and powders recovery ratio of the voloxidizer and remote operability in limited space, the reactor design should be optimized and modularized. To this end, this study investigated the engineering design of the voloxidizer in four stages: mechanism design, reactor design, modular design, and performance testing. First, to enhance the recovery ratio of the oxidation device, the oxidation performance of the current device prototype was tested. Next, to design the main voloxidizing mechanism, we evaluated various mechanical and chemical voloxidizing methods. On 


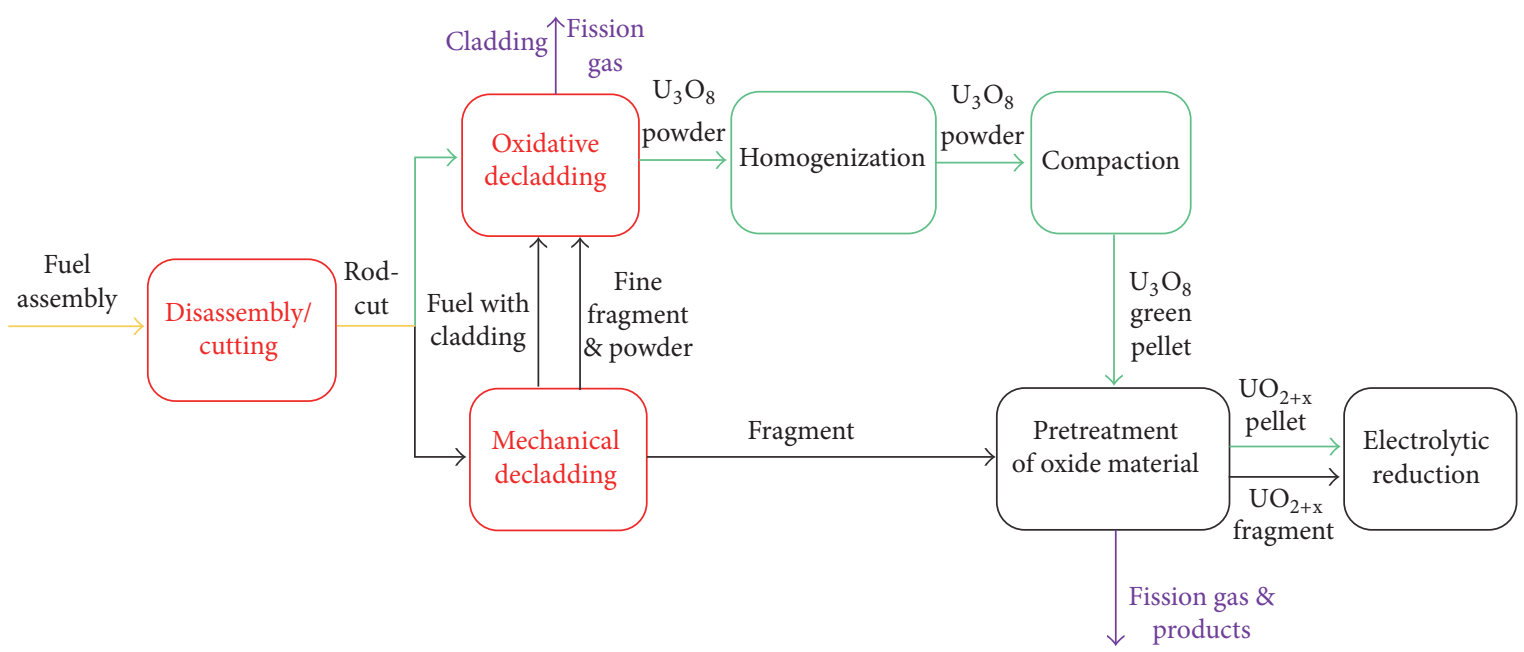

FIGURE 1: Flow chart of the head-end process.

the basis of the results, we selected the screw-and-rotation method for the double rotary drum [4]. Regarding the reactor design, volume constants were obtained for various tube lengths, using which a theoretical equation was derived. Subsequently, three-dimensional (3D) reactor models were designed using the theoretical equation and SolidWorks design software. Verification tests on an acryl vessel and zircaloy-4 (zry-4) tubes of various weights and lengths revealed that the developed models were highly accurate, with errors of only $0.02 \%-0.04 \%$.

For the modular design of the device, we selected the main components, namely, the heater, utility, motor, reactor, valve, and structure, and the remote assembling and disassembling possibility of the selected components were analyzed in terms of such factors as visibility, interference, approach, and weight to obtain the modular design most suited for the target modules.

A voloxidizer with a double reactor incorporating all the proposed improvements was designed and manufactured. To determine its hull-recovery ratio, a second hull-separation preperformance test was conducted using a $30 \mathrm{~mm}$ hull and simulated powder (balls) at a load of $50 \mathrm{~kg} \mathrm{HM} / \mathrm{batch}$. Finally, the remote assembling and disassembling possibility of the modules were verified using a crane and a manipulator.

\section{Design of the Voloxidizer with a Double Reactor}

2.1. Head-End Process. Figure 1 is a flow chart of the headend process. The head-end process technology, one of the key pyroprocessing technologies for treating oxide spent fuels, has seen considerable progress since it was proposed by KAERI in the late nineties. The main objectives of pyroprocessing are to reduce the heat load, radioactivity, and volume of the processed spent fuels by removing the heatgenerating elements and transforming the oxide fuels into metal fuels for disposal and/or recycling [5]. This process is comprised of two major separate processes: voloxidation and compaction. In the voloxidation stage, pellet-type spent fuels are pulverized through oxidation under blowing air; this flow removes some volatile fission products from the resulting $\mathrm{U}_{3} \mathrm{O}_{8}$ powder [6]. Subsequently, in the compaction stage, the $\mathrm{U}_{3} \mathrm{O}_{8}$ powder is processed in a compactor to form $\mathrm{U}_{3} \mathrm{O}_{8}$ pellets. The recovery efficiency of this compaction process depends on the hull-powder separation capacity.

In this study, the double-reactor voloxidizer was optimized in four stages: mechanism design, reactor design, modular design, and performance verification (Figure 2). In addition, we examined the hull-recovery efficiency of the device.

2.2. Mechanism Design. To enhance the hull-recovery ratio of the oxidation device, first, the hull-separation performance of the current device prototype was tested using a furnace revolving at $5 \mathrm{rpm}$ and $132 \mathrm{Zry}-4$ hulls with a length of $50 \mathrm{~mm}$ and a weight of $2.5 \mathrm{~kg}$ (132: number of hulls) as the load at $500^{\circ} \mathrm{C}$ (Figure 3). The measured hull-recovery ratio was $98 \%$. The remaining $2 \%$ could not be recovered as hulls entered the recovery container before the oxidation was complete; this was due to the high acceleration, $45^{\circ}$ inlet angle, and centrifugal force of the rotating reactor as well as the difference in the thermal expansion of the SUS-304 screw and the zircaloy rods caught inside the reactor.

Second, to design the main voloxidation mechanism, we evaluated various mechanical methods-slitting, ball milling, and roller straightening-and chemical methods-muffle furnace and rotary kiln-of voloxidation $[7,8]$. On the basis of the results, we selected the screw-and-rotation method for the double rotary drum to increase the hull-recovery ratio. As shown in Figure 4, through this approach, pellets in the rod-cuts could be easily oxidized at $500^{\circ} \mathrm{C}$, and, after oxidation, the hulls could be separated using the backlashing mechanism of the screw. Thus, we derived a voloxidizing mechanism for decladding spent fuel rods with high recovery efficiency by utilizing a double-reactor mechanism, wherein an internal reactor and external reactor are used to obtain 


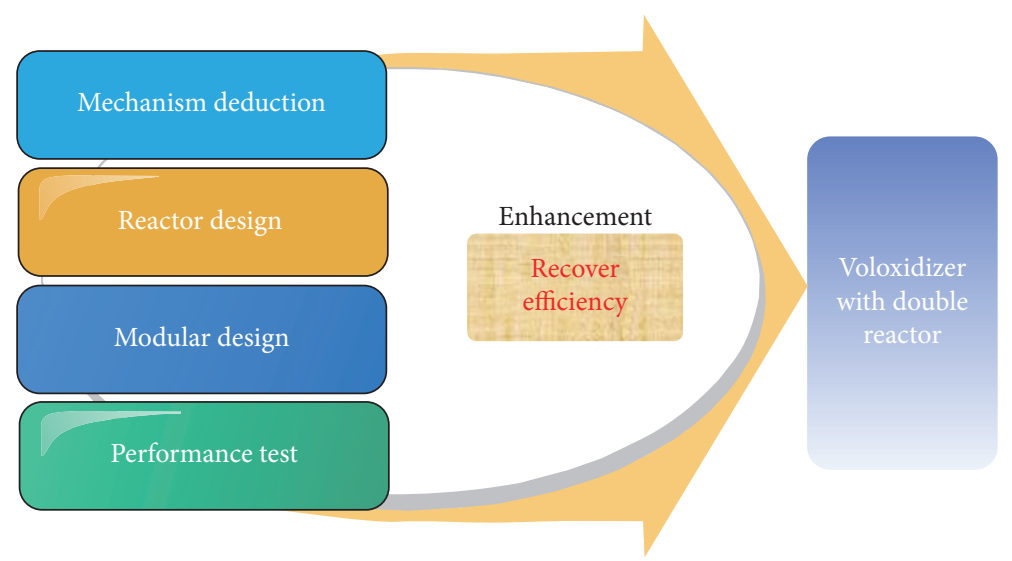

FIGURE 2: Double-reactor voloxidizer optimization stages/considerations.

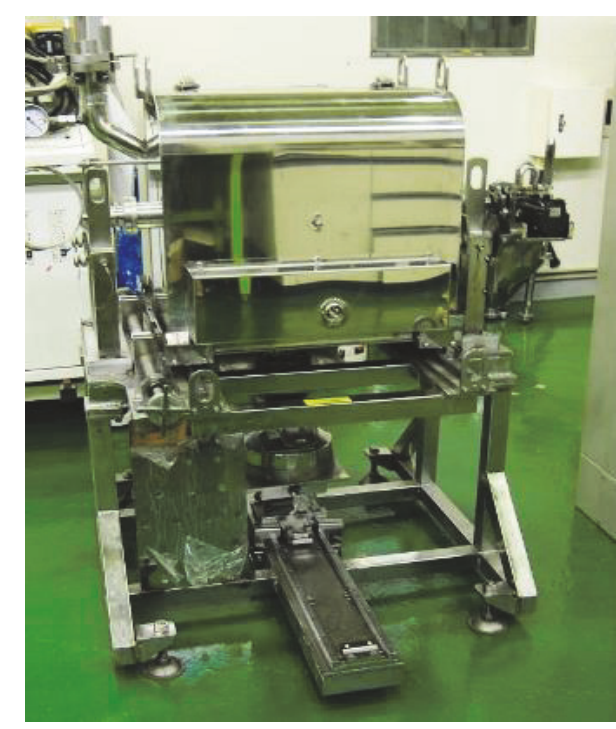

(a)

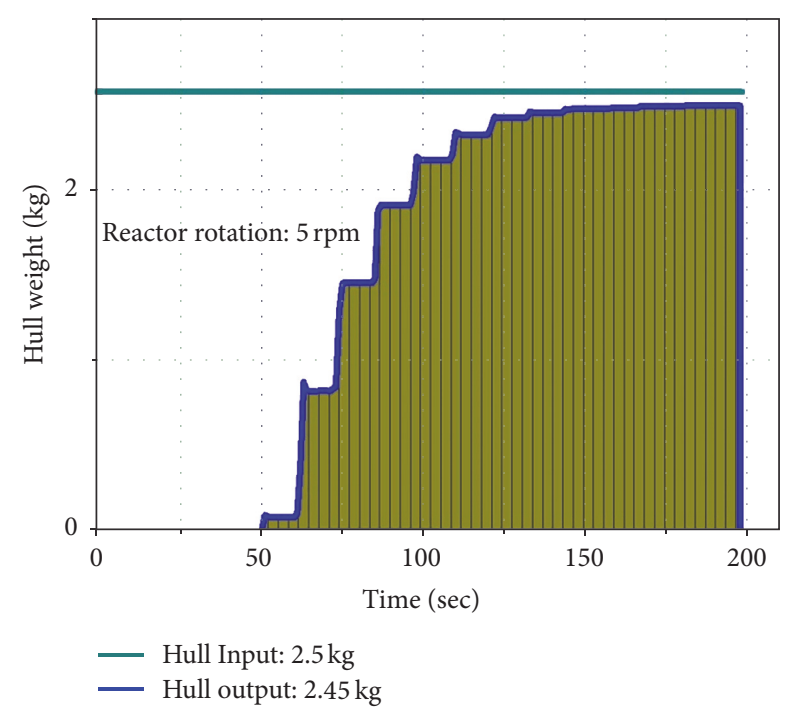

(b)

FIGURE 3: Hull-separation testing of the prototype device: (a) prototype; (b) separation results.

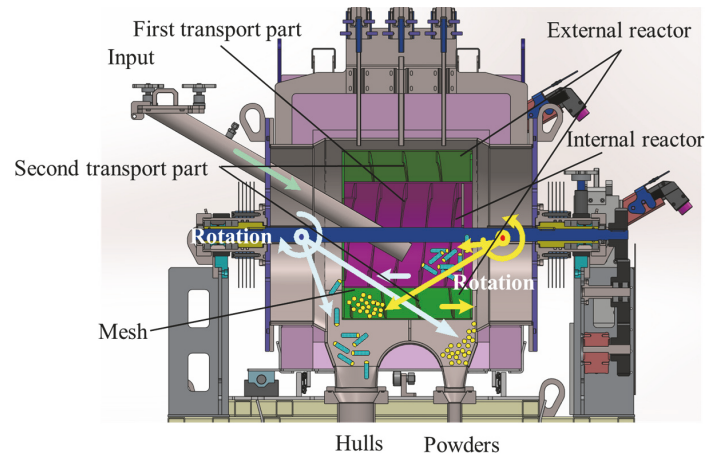

FIGURE 4: Separation of hulls and powder using the screw-androtation method.

stable oxide powder while simultaneously separating pellets and hulls.
In this approach, the double-reactor voloxidizer for decladding spent fuel rods includes a reactor module with a double-reactor structure, a heater module for heating the reactor module, and a drive module for driving the reactor module [9]. The double-reactor comprises an internal reactor, into which the spent fuel rods are loaded, and an external reactor, which forms the outer circumferential surface of the internal reactor. The first and second transport parts are formed on the inside surfaces of the internal and external reactors, respectively, and the spent fuel rods are moved into the first and second transport parts and oxidized when the internal and external reactors are rotated, respectively.

The reactor is first rotated in the clockwise direction for $8 \mathrm{~h}$, during which the spent fuel rods loaded in the internal reactor are moved toward the input part by the first transport part and are oxidized; subsequently, the rods in the internal reactor are moved by gravity to the external reactor through the internal mesh, where they are fully oxidized. Next, the 


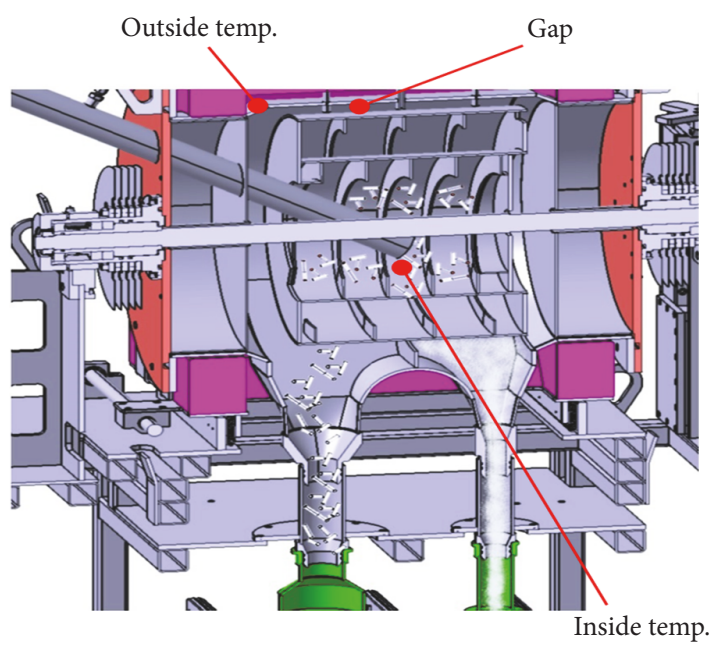

FIgURE 5: Model used to analyze the temperature variation in the reactor with change in the gap between the heater and the reactor.

reactor is rotated in the counterclockwise direction for $8 \mathrm{~h}$, during which time the oxidized rods are moved toward the drive module and divided into pellets and hulls. In other words, when the reactor is rotated in the clockwise direction, the spent fuel rods are moved to one end of the internal reactor and are oxidized; during this movement, the rods do not pass through the internal mesh. Later, the rods are pulled through the internal mesh and are moved to the external reactor by gravity. Next, when the reactor is rotated in the counterclockwise direction, the fully oxidized rods are moved to the other end of the external reactor and are discharged as pellets and hulls through the respective outlets.

The new design of the voloxidizer was subject to thermal and mechanical analysis using SolidWorks, a design software package, and COSMOSWorks, an analysis software package (Figures 5-7). The materials of some components, such as the shaft, mesh, and heater modules, were subject to thermal analysis [10] under the following boundary conditions: reactor material $=$ Inconel 601 , temperature $=500^{\circ} \mathrm{C}$, and pressure $=$ atmospheric pressure.

To optimize the reactor temperature, we measured the variation in temperature with change in the gap between the heater and the reactor $(25,35$, and $45 \mathrm{~cm})$. The results showed that a gap of $35 \mathrm{~mm}$ protected the lower valve components. In addition, we analyzed the heat-transfer characteristics in the range of $250-750^{\circ} \mathrm{C}$ (Figure 6) [11] with a reactor-heater gap of $35 \mathrm{~mm}$. The results indicated that, to maintain the optimal temperature $\left(500^{\circ} \mathrm{C}\right)$ in the reactor, the outlet temperature of the reactor should be more than $600^{\circ} \mathrm{C}$.

We performed deformation analysis to determine the appropriate rotating shaft diameter under the following boundary conditions: (1) reactor material = Inconel 601; (2) the weight of the components, including fuel, fixed to the rotating shaft $=$ a distributed load of $95 \mathrm{~kg}$; (3) maximum shaft surface temperature $=800^{\circ} \mathrm{C}$; (4) the shaft is fixed to the bearing at both ends, and (5) shaft diameter $=50 \mathrm{~mm}$. The analysis results presented in Figure 7 indicate that a shaft of diameter $50 \mathrm{~mm}$ has adequate structural strength and is safe.

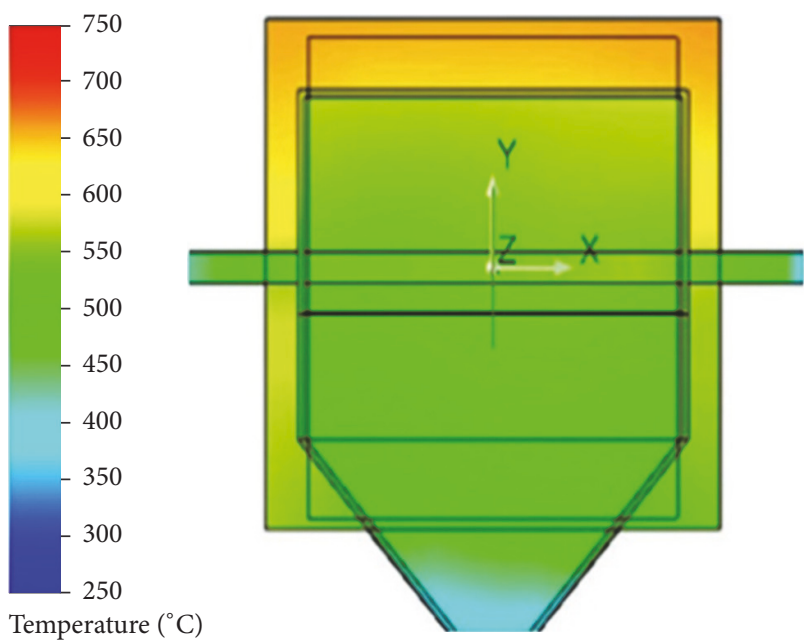

FIgURE 6: Heat-transfer characteristics of the reactor.

TABLE 1: Bulk and compacted volume ratios as a function of tube length.

\begin{tabular}{lcc}
\hline $\begin{array}{l}\text { Tube length } \\
(\mathrm{cm})\end{array}$ & $\begin{array}{c}\text { Bulk volume ratio } \\
\text { (constant) }\end{array}$ & $\begin{array}{c}\text { Compacted volume } \\
\text { ratio (constant) }\end{array}$ \\
\hline 2.0 & 1.9910 & 1.6660 \\
3.0 & 2.1140 & 1.7780 \\
5.0 & 2.3580 & 1.9760 \\
7.0 & 2.6590 & 2.2690 \\
9.0 & 2.9470 & 2.5180 \\
10.0 & 3.0810 & 2.6320 \\
\hline
\end{tabular}

2.3. Reactor Design. To obtain rod-cuts of a constant volume, we used rod-cut dimensions used in the Young Gwang spent fuel model (PWR: Pressurized Water Reactor, $16 \times 16$; outer diameter $=9.5 \mathrm{~mm}$ ).

We measured the bulk (no vibration) and compact (vibration for $20 \mathrm{~min}$ ) volume variation in tubes of various lengths $(2,3,5,7,9$, and $10 \mathrm{~cm})$ using a 2-liter beaker and by applying (1) and (2), respectively (Table 1 and Figure 8):

$$
\begin{aligned}
\text { Bulk volume ratio } & =\frac{\text { tube volume }}{\text { volume after cutting }}, \\
\text { Compacted volume ratio } & =\frac{\text { tube volume }}{\text { volume after vibration }},
\end{aligned}
$$

where tube volume is total volume when the tubes are piled side by side.

The bulk and compacted volume ratios of the rod-cuts can be obtained using (3) and (4), respectively:

$$
\begin{aligned}
& f_{B i}=Y_{1}+A_{1} \cdot X=1.702+0.1369 \cdot X, \\
& f_{C i}=Y_{2}+A_{2} \cdot X=1.405+0.1224 \cdot X,
\end{aligned}
$$

where $f_{B i}$ is bulk volume constant, $f_{C i}$ is compacted volume constant, $Y_{1}$ and $Y_{2}$ are $y$-axis intercepts, $A_{1}$ and $A_{2}$ are slant, and $X$ is cutting length. 


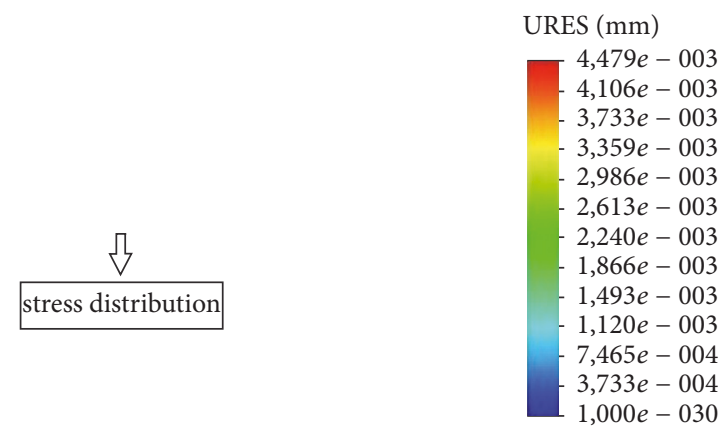

FIGURE 7: Shaft deformation analysis (50 $\mathrm{mm}$ diameter).

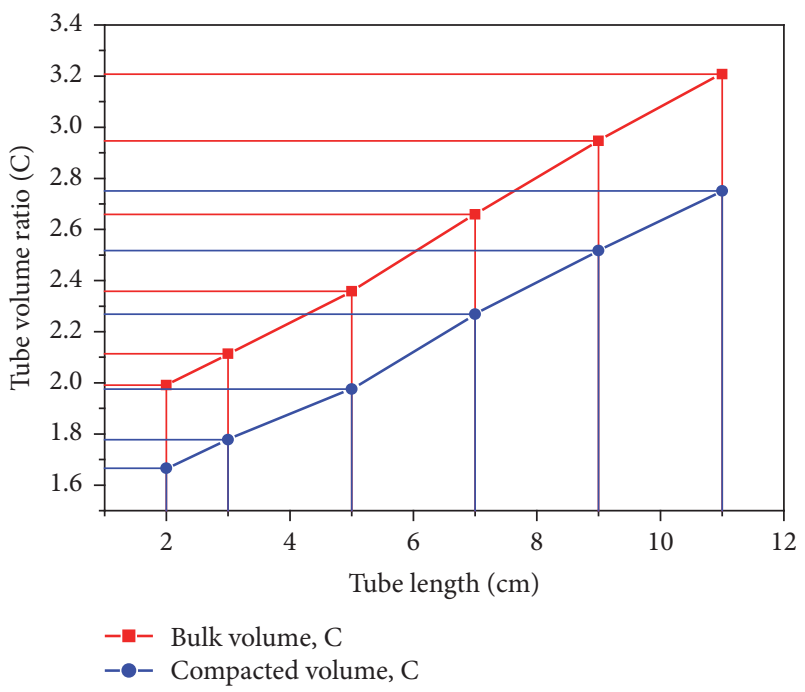

FIgURE 8: Tube volume ratio as a function of tube length.

The bulk rod-cut volume can be calculated as follows.

First, the volume of one rod-cut is obtained by multiplying its shearing sectional area $\left(\pi D^{2} / 4\right)$ and rod-cut length $\left(L_{i}\right)$. Second, the total volume of the pile of rod-cuts is obtained by multiplying the number of rod-cuts $\left(N_{i}\right)$ with the volume of each rod-cut $\left(L i \bullet \pi D^{2} / 4\right)$. Then, the total bulk volume of the rod-cut can be obtained by multiplying the total piled volume of the rod-cut $\left(L i \cdot N \cdot \pi D^{2} / 4\right)$ and the rod-cut volume constant $\left(f_{B i}\right)$. Finally, the actual bulk volume of the rod-cut $\left(V_{t}\right)$ can be obtained by adding the total bulk volume of the rod-cut $\left(f_{i} \bullet L i \cdot N \cdot \pi D^{2} / 4\right)$ and the shaft volume $\left(\pi d^{2} / 4 \bullet \ell_{i}\right)$, as shown in (5) and Figure 9. Here, the outlet diameter of the rod-cut differs by the type of the spent fuel assembly. Nevertheless, even if the types of spent fuel assembly change, the volume constant of the rod-cut remains fixed

$$
V_{t}=f_{B i} L_{i} N_{i} \frac{\pi D^{2}}{4}+\frac{\pi d^{2}}{4} \ell_{i}
$$

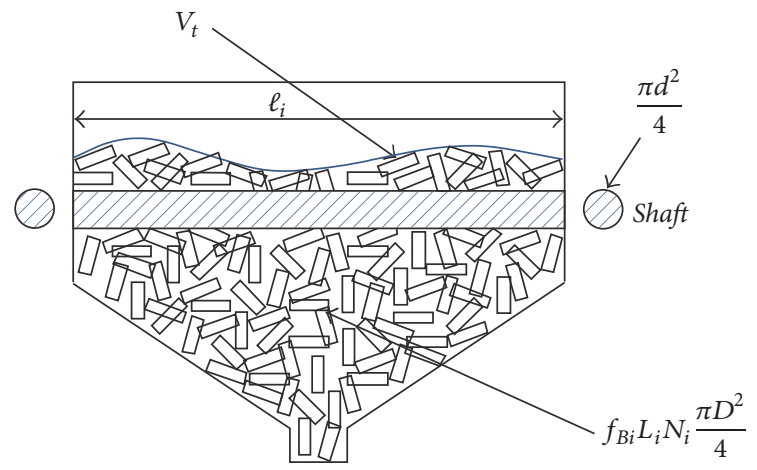

FIGURE 9: Structural diagram of reactor showing total piled volume and shaft volume.

where $V_{t}$ is actual bulk volume of the rod-cuts, $f_{B i}$ is volume constant of the rod-cuts, $L_{i}$ is rod-cut length, $N_{i}$ is number of rod-cuts, $\pi D^{2} / 4$ is the shearing sectional area of each rodcut, $f_{i} \bullet L i \bullet N \bullet \pi D^{2} / 4$ is total bulk volume of the rod-cuts, $\pi d^{2} / 4$ is shaft sectional area, and $\ell_{i}$ is shaft length.

Using the rod-cut volume equation, 3D models of the reactor and an acryl vessel were designed using SolidWorks for various rod-cut lengths and weights [12] under the following reactor design conditions (Figures 10 and 11):

(1) Boundary condition: inner diameter $=300 \mathrm{~mm}$.

(2) The reactor is $50 \%$ filled with rod-cuts.

(3) Spent fuel $=5,20,50$, and $100 \mathrm{~kg}$.

(4) Hull lengths $=3,5,7$, and $10 \mathrm{~cm}$.

To verify this theoretical equation, centimeter-scale reactors and hulls with the given weights and lengths indicated above were manufactured (Figure 12) from acryl and $9.5 \mathrm{~mm}$ zry-4 tubes, respectively. The hulls were filled in the acryl reactors and the occupied volumes were measured as a function of their weights and lengths. The result showed that the theoretical equation had errors of only $0.02 \%-0.04 \%$ (Figure 13). 


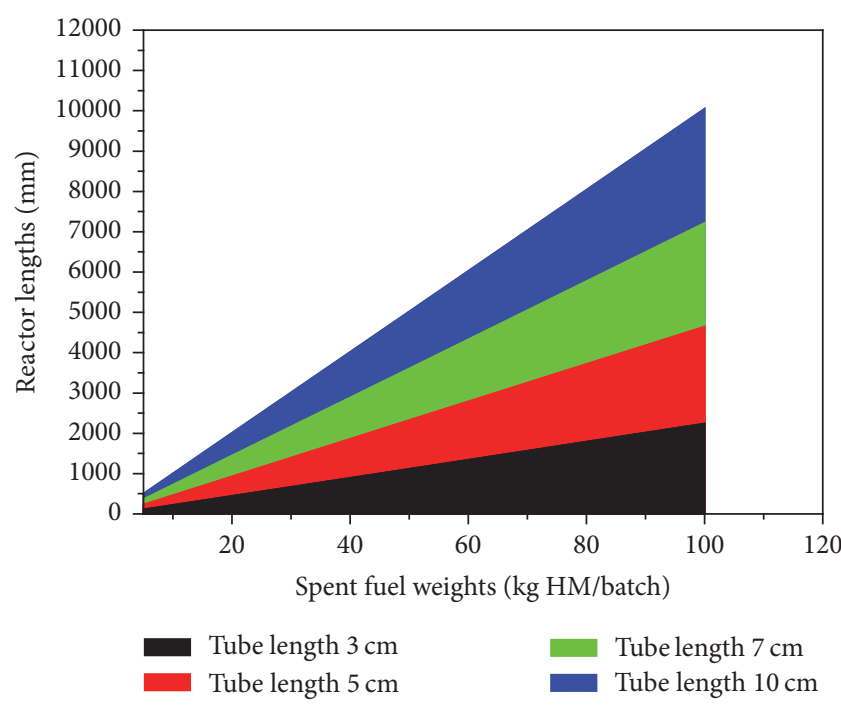

FIGURE 10: Reactor length for various hull lengths as a function of spent fuel weight.

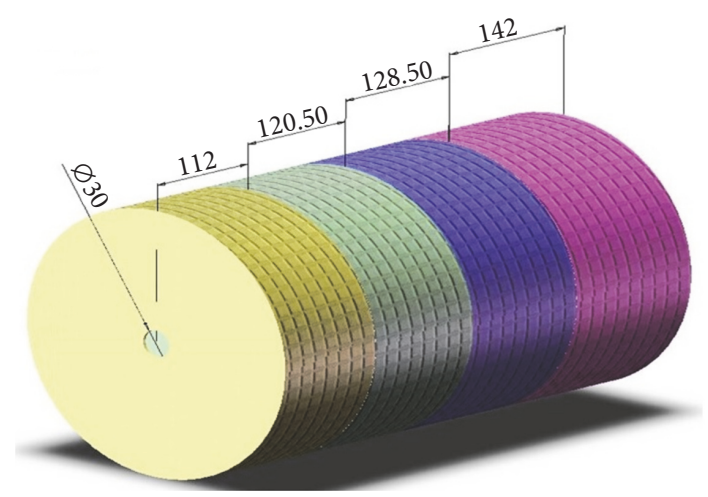

FIGURE 11: Reactor size as a function of hull length at a spent fuel load of $50 \mathrm{~kg} \mathrm{HM} / \mathrm{batch}$.

2.4. Modular Design. We reviewed the literature on modular design and found that, in general, a modular design is very difficult to apply to all the process devices $[13,14]$. Therefore, only the main components, namely, the heater, utility, motor, reactor, valve, and structure (Figures 14(a)-14(b)), were selected and modified for modularization. Moreover, we analyzed the remote operability and maintainability of the voloxidizer. The remote assembling and disassembling possibility of the selected modules were analyzed in terms of such factors as visibility, interference, approach, and weight, and we accordingly developed the final modular design. The modularization of these components-some of which are commercially available (e.g., bolt, flange, motor, and valve) and some of which are unique (e.g., reactor)-has been previously analyzed $[15,16]$.

The voloxidizer was modeled using SolidWorks, as shown in Figure 15. The new double-reactor voloxidizer provides a mechanism for processing spent nuclear fuel and is capable of pulverizing rod-cuts using air and heat; its modular structure

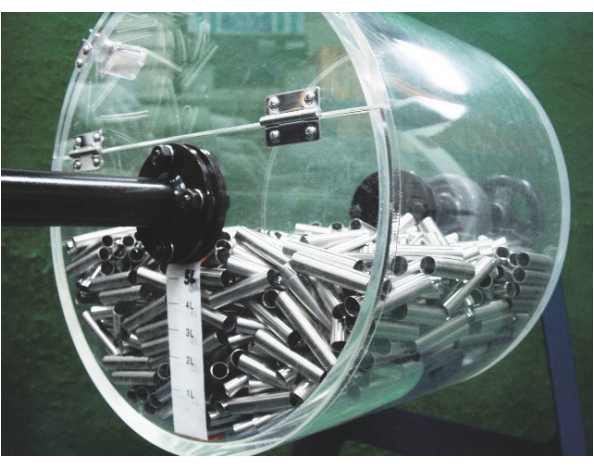

FIGURE 12: Hull volume in an acryl reactor (the volume is indicated by liter $(\mathrm{L})$ on the ordinate axis, weight $=20 \mathrm{~kg}$, and length $=50 \mathrm{~mm}$ ).

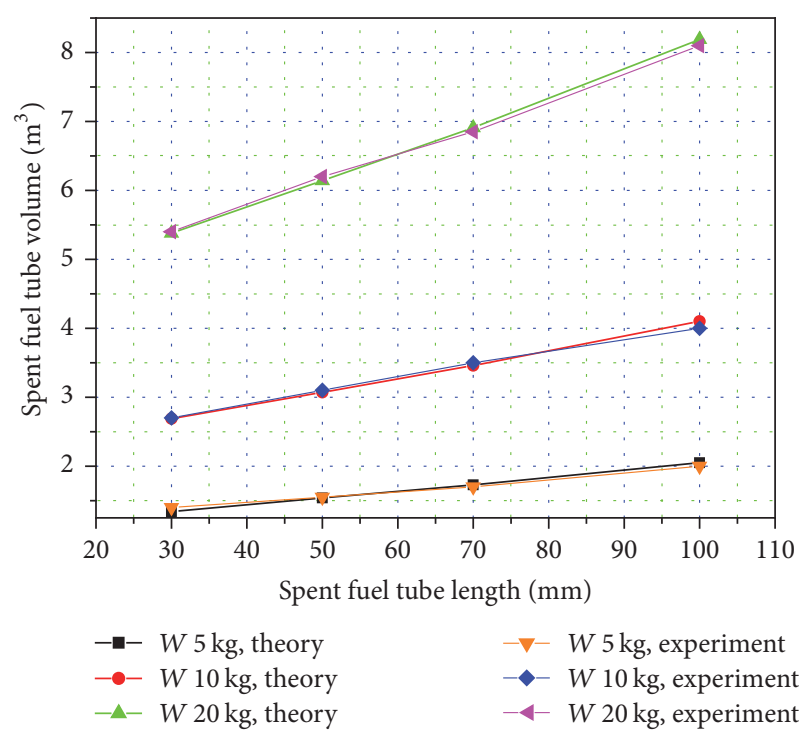

FIGURE 13: Rod-cut volume as a function of rod-cut length and weight.

renders it easy to maintain and repair remotely, and the operators can remain far from the highly radioactive hot cell.

The modeled voloxidizer has the following components: a voloxidizer capable of processing $50 \mathrm{~kg}$ of spent nuclear fuel, reactor module in which the spent nuclear fuel is placed and oxidized, heating module that heats the reactor module to a high temperature, utility module to control the inner conditions of the reactor module, support module to support the heating module and reactor module, drive module to move the spent nuclear fuel within the reactor module, valve module to control the discharge of the spent nuclear fuel in the reactor module, and collecting-container module to collect the discharged spent nuclear fuel. The respective modules can be assembled and disassembled [17].

\section{Results and Discussion}

3.1. Preliminary Separation Test. Figure 16(a) presents a decladding double-reactor structure that yields an improved 


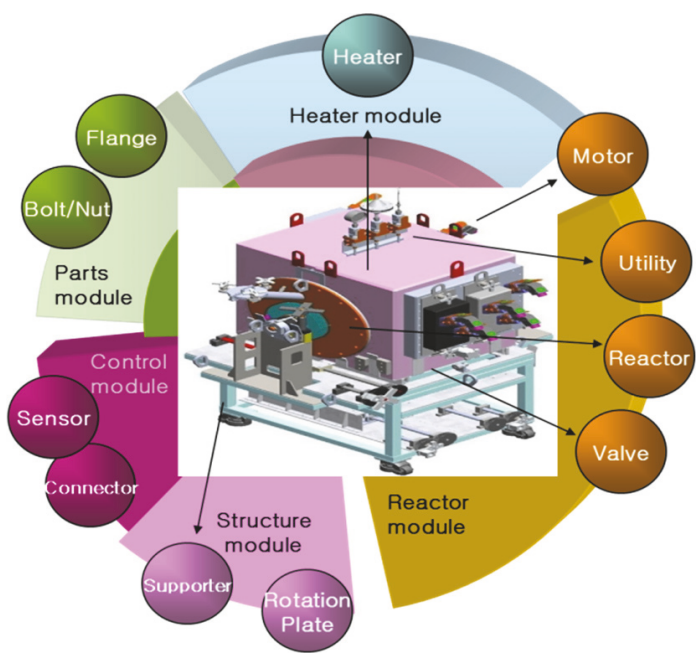

(a)
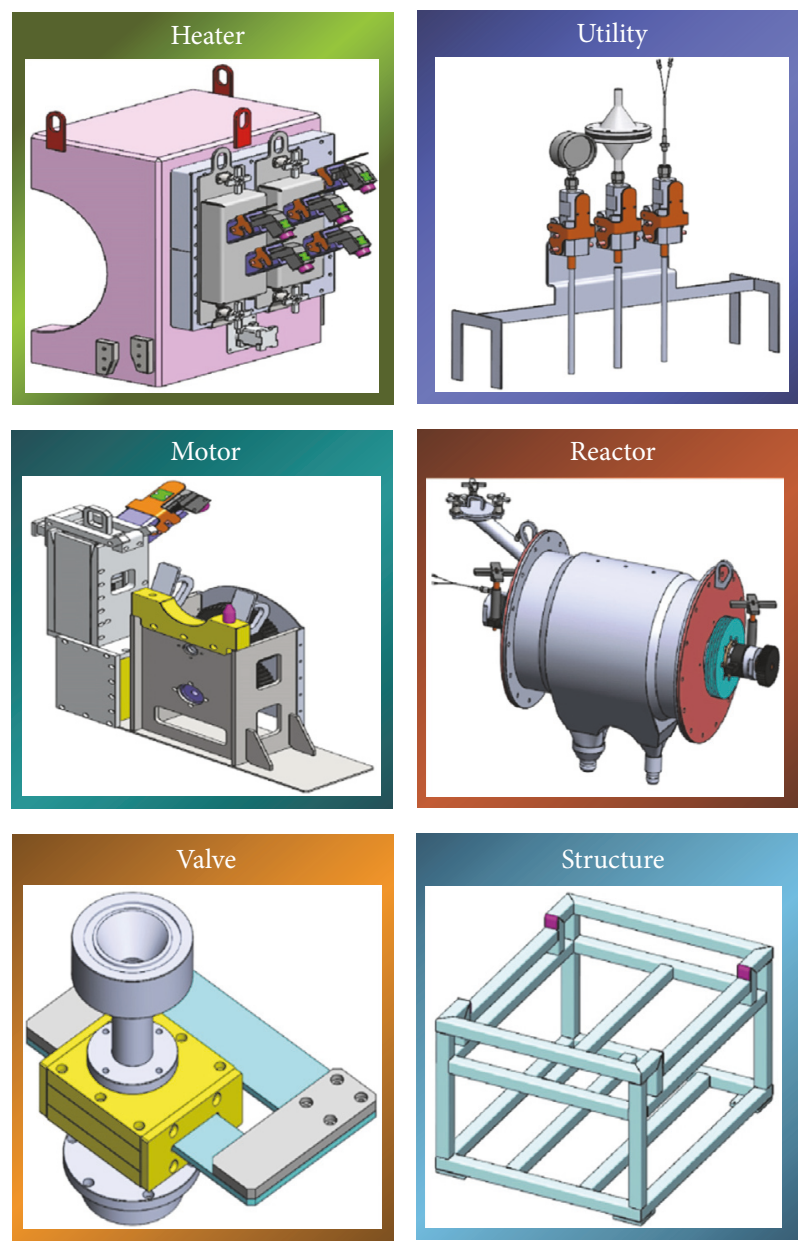

(b)

Figure 14: Modular design for a remotely operated voloxidizer: (a) main modules of the voloxidizer; (b) design modules.

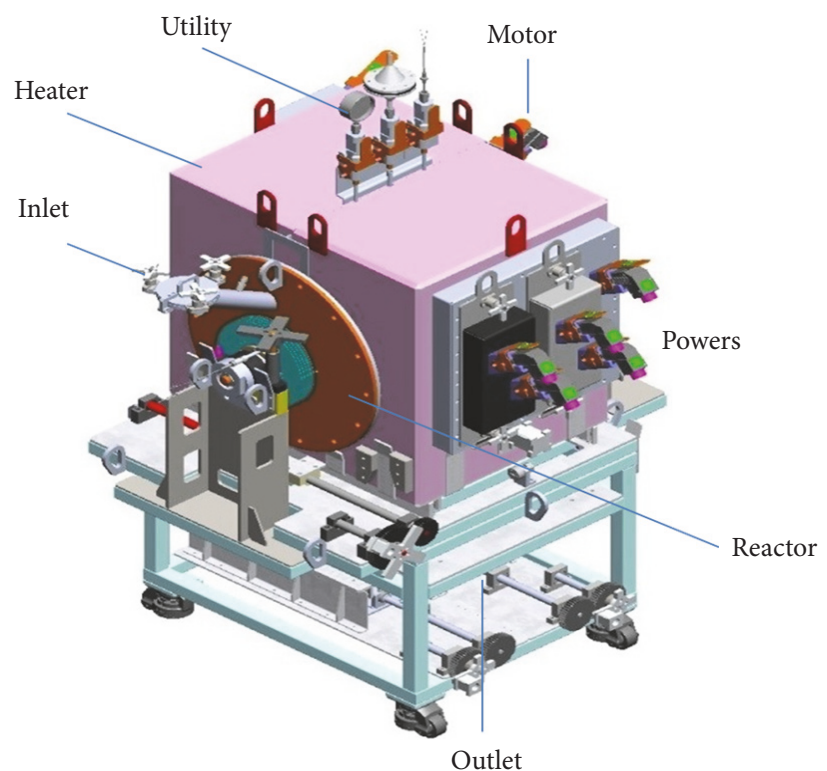

FIGURE 15: A 3D model of the voloxidizer. 
TABLE 2: Hull recovery ratios.

\begin{tabular}{|c|c|c|c|c|c|}
\hline Rod-cuts (kg) & Number of hulls & $\begin{array}{c}\text { Reactor rotation } \\
(\mathrm{rpm})\end{array}$ & Number recovered & $\begin{array}{c}\text { Recovery rate } \\
(\%)\end{array}$ & $\begin{array}{l}\text { Time } \\
\text { (s) }\end{array}$ \\
\hline & & 3 & 284 & 100 & 226 \\
\hline \multirow[t]{3}{*}{10} & 284 & 5 & 284 & 100 & 131 \\
\hline & & 10 & 284 & 100 & 75 \\
\hline & & 3 & 568 & 100 & 227 \\
\hline \multirow[t]{3}{*}{20} & 568 & 5 & 568 & 100 & 150 \\
\hline & & 10 & 568 & 100 & 78 \\
\hline & & 3 & 852 & 100 & 277 \\
\hline \multirow[t]{3}{*}{30} & 852 & 5 & 852 & 100 & 154 \\
\hline & & 10 & 852 & 100 & 82 \\
\hline & & 3 & 1136 & 100 & 279 \\
\hline \multirow[t]{3}{*}{40} & 1136 & 5 & 1136 & 100 & 165 \\
\hline & & 10 & 1135 & 100 & 98 \\
\hline & & 3 & 1420 & 100 & 327 \\
\hline \multirow[t]{2}{*}{50} & 1420 & 5 & 1419 & 100 & 171 \\
\hline & & 10 & 1418 & 100 & 99 \\
\hline
\end{tabular}

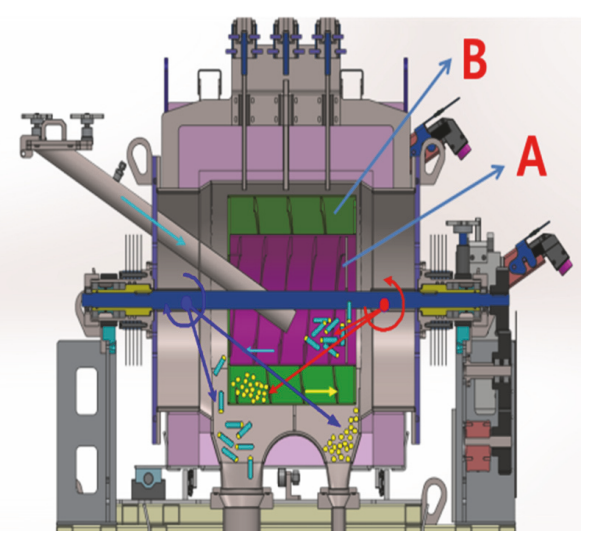

(a)

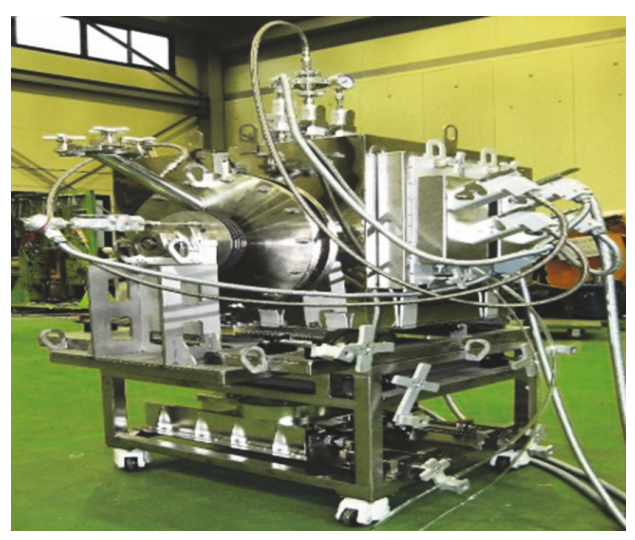

(b)

FIGURE 16: Optimized reactor and device: (a) double reactor; (b) voloxidizer.

hull and powder recovery ratio and pellet oxidation efficiency. As shown in the figure, the rod-cuts entering the inlet are inserted into rotating reactor $\mathrm{A}$ and are reacted at $500^{\circ} \mathrm{C}$; the pellets inside the rod-cuts are oxidized, and the powder drops to reactor $\mathrm{B}$ to form a uniform and stable oxidized powder. Next, on rotating the double reactor in the counterclockwise direction, the powder and hull are separated. Figure 16(b) shows the improved and modularized voloxidizer of length $1500 \mathrm{~mm}$, width $1200 \mathrm{~mm}$, and height $1600 \mathrm{~mm}$.

The improved voloxidizer was subject to preliminary hull and powder separation testing and recovery ratio measurements using 53 cut zry-4 hulls $(\emptyset 9.5 \times$ L30 mm), which correspond to $1 \mathrm{~kg}$ of spent fuel. Copper balls $(\emptyset 1 \mathrm{~mm}, 110 \mathrm{~g})$ were used as a substitute for the powder. In Uchiyama et al.s study [4], after the oxidation experiments, about 95-99 wt\% of the total amount of the initially charged fuel remained in the voloxidizer. However, at the improved voloxidizer, the powder and hull-recovery ratios were $100 \%$, and the recovery time was approximately $150 \mathrm{~s}$ (Figures $17(\mathrm{a})-17(\mathrm{c})$ ).
3.2. Voloxidizer Testing. The voloxidizer performance was tested as shown in Figure 18(a); no reactor gas leak was observed, and the reactor rotation operation, inlet and outlet valve operation, and remote operation test were all favorable at a reactor temperature of $500^{\circ} \mathrm{C}$ for $16 \mathrm{~h}$. As shown in Figure 18 (b), the heating rate, until it stabilized at $500^{\circ} \mathrm{C}$, was $3.3^{\circ} \mathrm{C} / \mathrm{min}(\sim 150 \mathrm{~min})$. However, an overvoltage was initially observed. In addition, at input oxygen concentrations $\left(\mathrm{O}_{2}\right)$ of $50 \%$ and $5 \%$, reactor saturation times were 37 and $150 \mathrm{~min}$, respectively.

3.3. Hull-Separation Tests. To confirm the recovery ratio of the reactor, the reactor and measurement system were tested, as shown in Figure 19, with a load of $50 \mathrm{~kg} \mathrm{HM} /$ batch under the following condition: reactor rotation rate $=3-20 \mathrm{rpm}$ with no vibrations. The recovery ratio was $100 \%$ in the range of $10-50 \mathrm{~kg}$ of rod-cuts at 3-10 rpm (Figures 20(a)-20(c) and Table 2). However, when the rotation rate exceeded $20 \mathrm{rpm}$, the hulls did not separate. To identify the reasons for this 


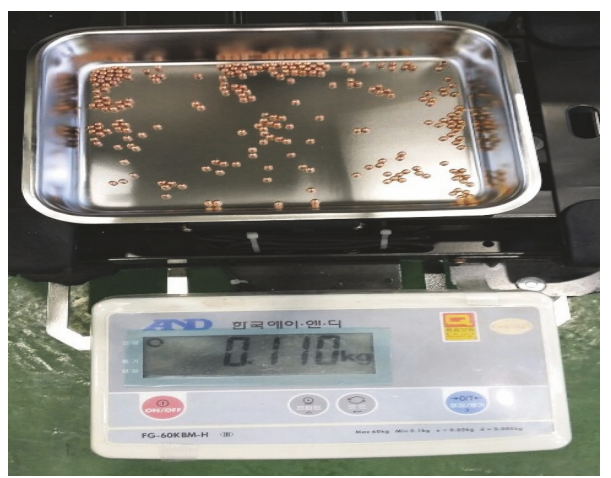

(a)

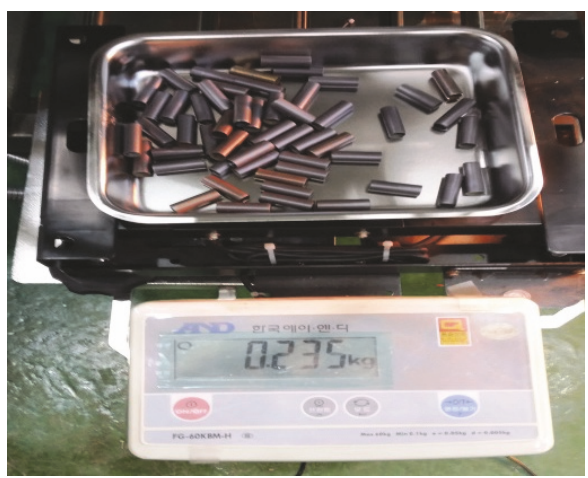

(b)

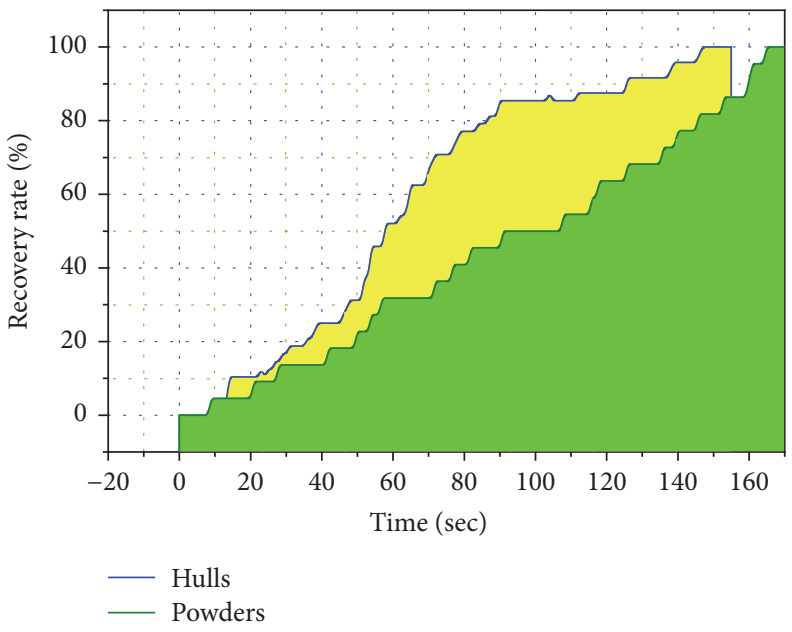

(c)

FIGURE 17: Recovery efficiency of (a) powder (balls) and (b) tubes (zry-4); (c) recovery efficiency over time.

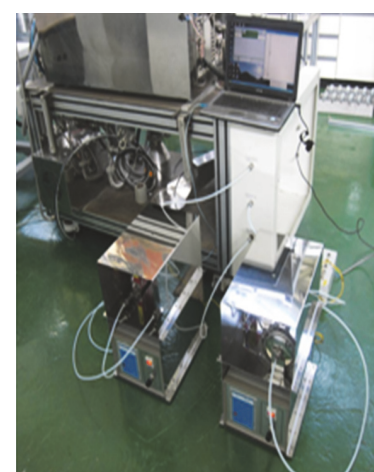

(a)

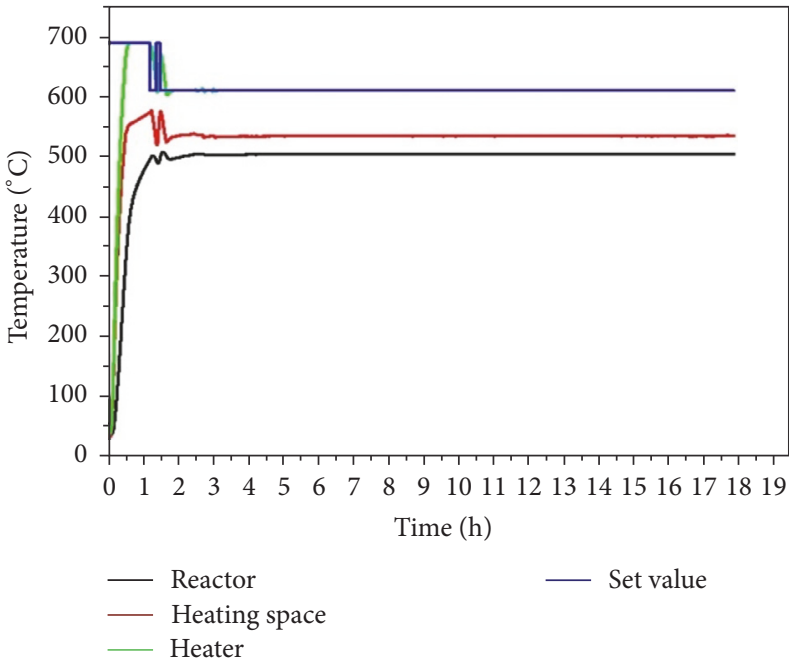

(b)

FIGURE 18: Heating test of the prototype device: (a) temperature test equipment; (b) test results. 


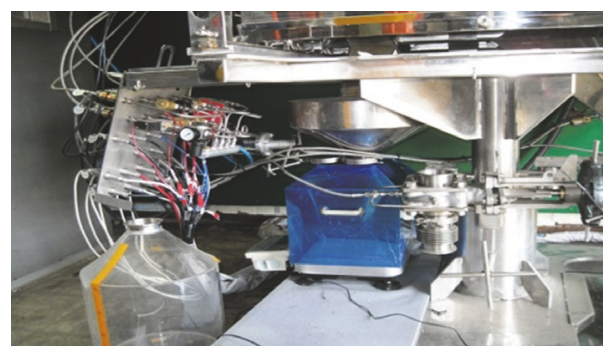

FIGURE 19: Hull-recovery ratio measurement equipment.

TABLE 3: Assembling and disassembling time of various modules.

\begin{tabular}{|c|c|c|c|}
\hline \multirow{2}{*}{ Modules } & \multicolumn{2}{|c|}{ Time (min) } & \multirow{2}{*}{ Possibility } \\
\hline & Disassembling & Assembling & \\
\hline Heater (2M) & 32 & 47 & Good \\
\hline Reactor & 53 & 72 & Good \\
\hline Motor & 12 & 21 & Good \\
\hline Valve $(2 \mathrm{~V})$ & 24 & 36 & Good \\
\hline
\end{tabular}

failure, an acryl reactor was manufactured according to the $3 \mathrm{D}$ model and tested. Test results revealed that the hulls failed to exit the reactor because of centrifugal force (Figure 20(d)).

3.4. Modularity Testing. The remote assembling and disassembling possibility of the modularized reactor were tested for verification with a spent fuel load of $50 \mathrm{~kg} \mathrm{HM} / \mathrm{batch}$ (Figure 21) using a crane and manipulator. The assembling and disassembling time of the modules varied between 53 and 72 min without any difficulty (Table 3 ).

\section{Conclusions}

A voloxidizer with a double reactor capable of processing several tens of kilograms of $\mathrm{HM} / \mathrm{batch}$ of nuclear spent fuel has been developed by KAERI for the decladding and voloxidation of rod-cuts into hulls and pellets through the conversion of $\mathrm{UO}_{2}$ pellets to $\mathrm{U}_{3} \mathrm{O}_{8}$ powder. In this study, the double-reactor voloxidizer was optimized in four stages: mechanism design, reactor design, modular design, and performance verification. In addition, we examined the hull-recovery efficiency of the device. To design the main voloxidizing mechanism, we evaluated various mechanical and chemical voloxidizing methods. On the basis of the results, we selected the screw-and-rotation method for the double rotary drum. Using the rod-cut volume equation, 3D models of the reactor and an acryl vessel were designed using SolidWorks for various rod-cut lengths and weights. The result showed that the theoretical equation had errors of only $0.02 \%-0.04 \%$. Subsequently, we modularized the main modules, namely, the heater, utility, motor, reactor, valve, and structure, and the remote assembling and disassembling possibility of the selected modules were analyzed in terms of such factors as visibility, interference, approach, and weight to obtain the modular design most suited for the target modules. To confirm the recovery ratio of the reactor, the reactor and measurement system were tested, as shown in Figure 19, with a load of $50 \mathrm{~kg} \mathrm{HM} / \mathrm{batch}$ under the following condition: reactor rotation rate $=3-20 \mathrm{rpm}$ with no vibrations. The recovery ratio was $100 \%$ in the range of $10-50 \mathrm{~kg}$ of rod-cuts at 3-10 rpm. However, when the rotation rate exceeded $20 \mathrm{rpm}$, the hulls did not separate. To identify the reasons for this failure, an acryl reactor was manufactured according to the 3D model and tested. Test results revealed that the hulls failed to exit the reactor because of centrifugal force. In addition, the remote assembling and disassembling possibility of the modularized reactor were tested for verification with a spent fuel load of $50 \mathrm{~kg} \mathrm{HM} / \mathrm{batch}$ (Figure 21) using a crane and manipulator. The assembling and disassembling time of the modules varied between 53 and $72 \mathrm{~min}$ without any difficulty. This design process can help in further optimizing the design of a compact voloxidizer with high efficiency.

$\begin{array}{ll}\text { Abbreviations } & \\ \mathrm{HM}: & \text { Heavy metal } \\ \text { rpm: } & \text { Revolutions per minute } \\ \mathrm{KAERI}: & \text { Korea Atomic Energy Research } \\ & \text { Institute } \\ \mathrm{UO}_{2}, \mathrm{U}_{3} \mathrm{O}_{8}: & \text { Uranium oxide } \\ \mathrm{SUS}: & \text { Steel use stainless } \\ \text { PWR: } & \text { Pressurized Water Reactor } \\ f_{B i}: & \text { Bulk volume constant } \\ f_{C i}: & \text { Compacted volume constant } \\ Y_{1} \text { and } Y_{2}: & y \text {-axis intercepts } \\ A_{1} \text { and } A_{2}: & \text { Slant } \\ X: & \text { Cutting length } \\ V_{t}: & \text { Actual bulk volume of the rod-cuts } \\ f_{B i}: & \text { Volume constant of the rod-cuts } \\ L_{i}: & \text { Rod-cut length } \\ L: & \text { Length } \\ N_{i}: & \text { Number of rod-cuts } \\ \pi D^{2} / 4: & \text { The shearing sectional area of each } \\ f_{i} \bullet L i \bullet N \bullet \pi D^{2} / 4: & \text { Total bulk volume of the rod-cuts } \\ \pi d^{2} / 4: & \text { Shaft sectional area } \\ \ell_{i}: & \text { Shaft length } \\ \text { e.g.: } & \text { Exempli gratia. }\end{array}$

\section{Disclosure}

Some part of this paper was printed in the proceeding of the KNS 2015 spring meeting (Jeju, Korea, May 7-8, 2015). 

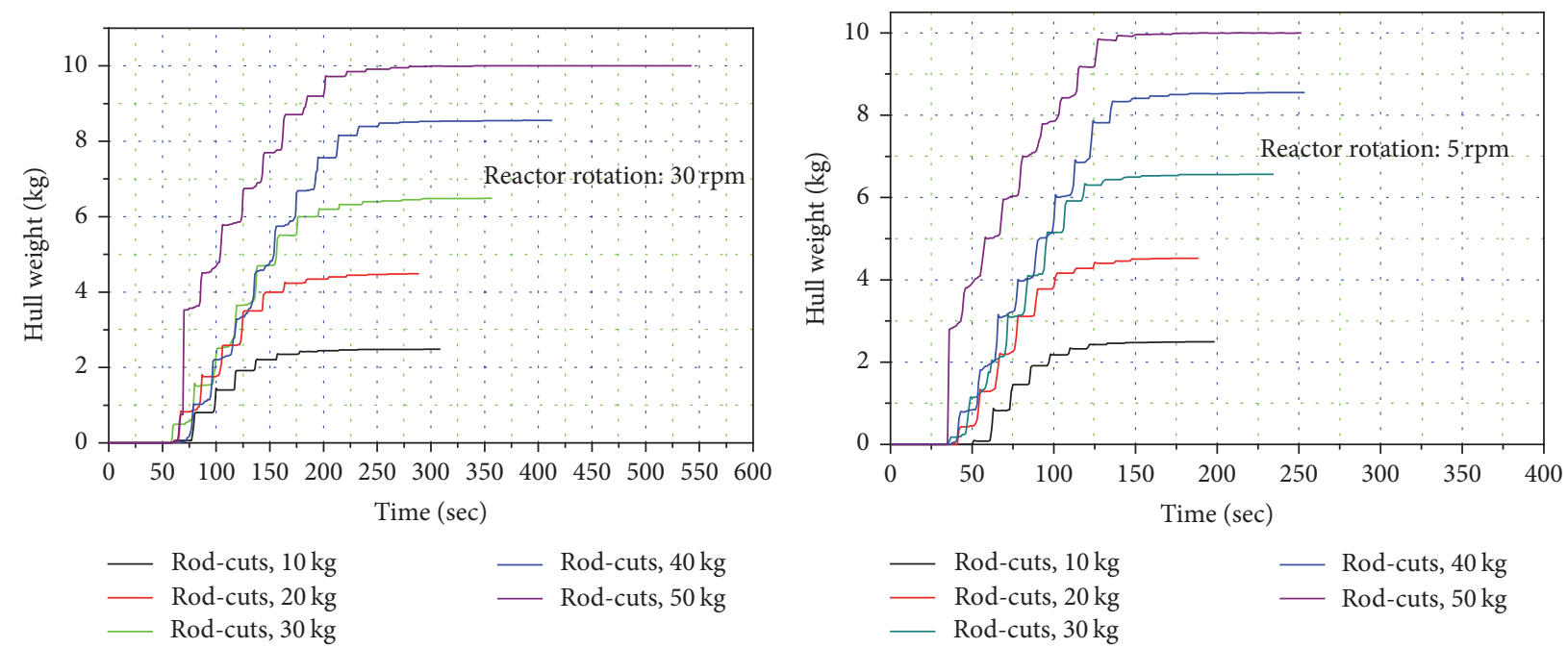

(a)

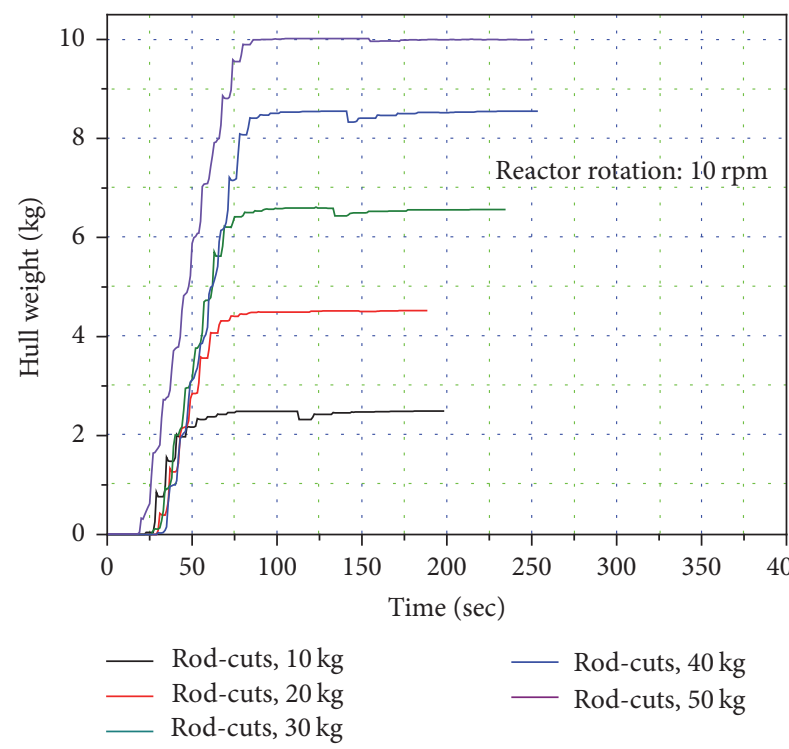

(c)

(d)

FIGURE 20: Hull recover ratio as a function of hull weight and reactor rotation of (a) $3 \mathrm{rpm}$, (b) $5 \mathrm{rpm}$, (c) $10 \mathrm{rpm}$, and (d) $20 \mathrm{rpm}$.

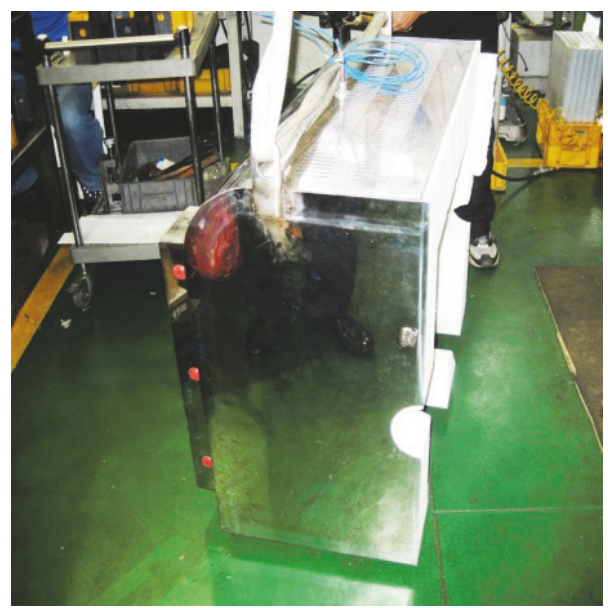

(a)

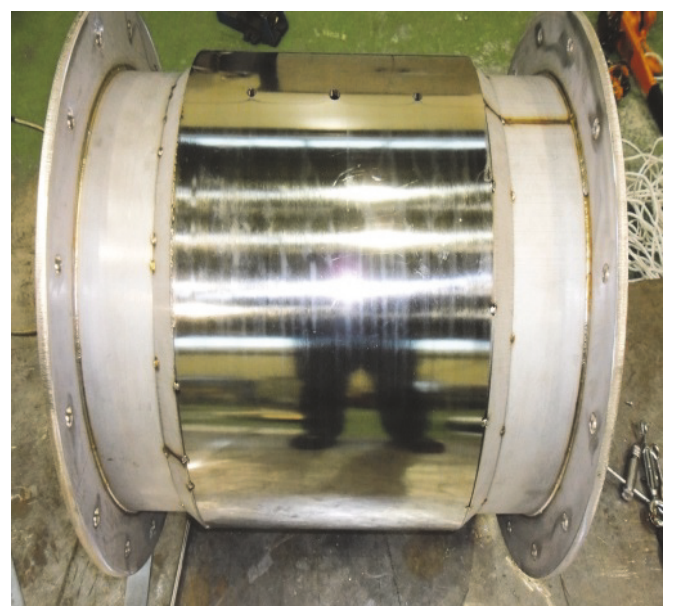

(b)

FIGURE 21: Testing the assembling and disassembling possibility of modules: (a) heater; (b) reactor. 


\section{Conflicts of Interest}

The authors declare that they have no conflicts of interest regarding publishing this research article.

\section{Acknowledgments}

This study was supported by Grant 2012M2A8A5025696 from the National Research Foundation of Korea, which is funded by the Ministry of Science and Technology, Republic of Korea.

\section{References}

[1] J.-H. Yoo, C.-S. Seo, E.-H. Kim, and H.-S. Lee, "A conceptual study of pyroprocessing for recovering actinides from spent oxide fuels," Nuclear Engineering and Technology, vol. 40, no. 7, pp. 581-592, 2008.

[2] K.-C. Song, H. Lee, J.-M. Hur, J.-G. Kim, D.-H. Ahn, and Y.Z. Cho, "Status of pyroprocessing technology development in Korea," Nuclear Engineering and Technology, vol. 42, no. 2, pp. 131-144, 2010.

[3] H.-S. Lee, G.-I. Park, J.-W. Lee et al., "Current status of pyroprocessing development at KAERI," Science and Technology of Nuclear Installations, vol. 2013, Article ID 343492, 11 pages, 2013.

[4] G. Uchiyama, M. Kitamur, and K. Yamazaki, "Development of voloxidation process for tritium control in reprocessing," Japan Atomic Energy Research Institute-M, pp. 91-199, 1991.

[5] M. F. Simpson, "Projected salt waste production from a commercial pyroprocessing facility," Science and Technology of Nuclear Installations, vol. 2013, Article ID 945858, 8 pages, 2013.

[6] Y. H. Kim, H. J. Lee, J. K. Lee et al., "Engineering design of a high-capacity vol-oxidizer for handling UO2 pellets of tens of kilogram," Journal of Nuclear Science and Technology, vol. 45, no. 7, pp. 617-624, 2008.

[7] F. H. Hammad, H. R. Higgy, and A. A. Abdel-Rsddoul, "Mechanical decladding of nuclear fuel elements," Journal of the British Nuclear Energy Society, vol. 10, no. 1, pp. 21-28, 1971.

[8] M. R. Bradford, "Chemical processes in the oxidation and degradation of AGR oxide fuel," Nuclear Energy, vol. 35, no. 5, pp. 321-330, 1996.

[9] G. Uchiyama, S. Torikai, and M. Kitamura, "Outline of an experimental apparatus for the study on the advanced voloxidation process," Japan Atomic Energy Research Institute-M, pp. 90-016, 1990.

[10] S. R. Dharwadkar and M. D. Karkhanavara, "High temperature oxidation of uranium dioxide: Part II.-pressure and temperature dependence of the oxidation rate," Indian Journal of Chemistry, vol. 13, pp. 685-688, 1975.

[11] K. A. Peakall and J. E. Antill, "Oxidation of uranium dioxide in air at 350-1000॰C," Journal of Nuclear Materials, vol. 2, no. 2, pp. 194-195, 1960.

[12] J. Alagy, P. Trambouze, and H. Van Landeghem, "Designing a cyclohexane oxidation reactor," Industrial and Engineering Chemistry: Process Design and Development, vol. 13, no. 4, pp. 317-323, 1974.

[13] L. Steffensen, O. Than, and S. Büttgenbach, "BICEPS: a modular environment for the design of micromachined silicon devices," Sensors and Actuators A: Physical, vol. 79, no. 1, pp. 76-81, 2000.
[14] W. Yan, "Functionality-based modular design for mechanical product stomization over the Internet," Journal of Design and Manufacturing Automation, vol. 4, no. 1, pp. 37-46, 2001.

[15] H. Chun-Ch, "Overview of modular product development , Proceedings of National Science Council," vol. 24, pp. 149-165, 2000.

[16] Y.-T. Tsai and K.-S. Wang, "Development of modular-based design in considering technology complexity," European Journal of Operational Research, vol. 119, no. 3, pp. 692-703, 1999.

[17] D. W. He and K. Andrew, "Design of assembly systems for modular products," IEEE Transactions on Robotics and Automation, vol. 13 , no. 5, pp. 646-655, 1997. 


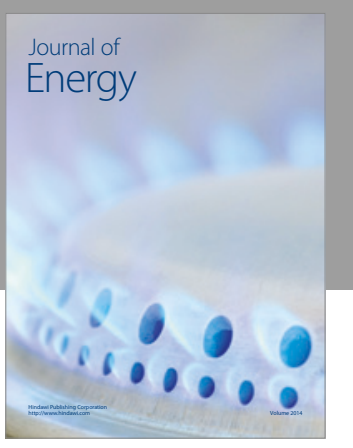

Journal of

Industrial Engineering
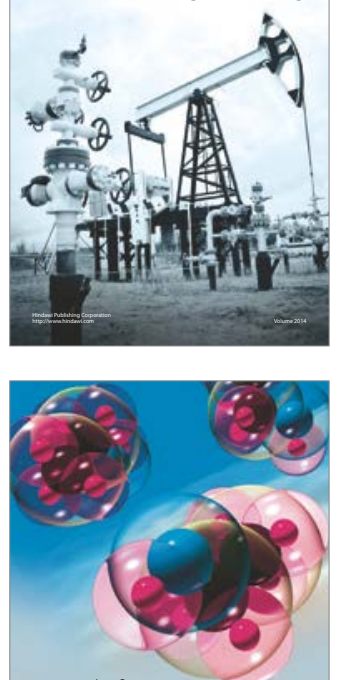

Fuels
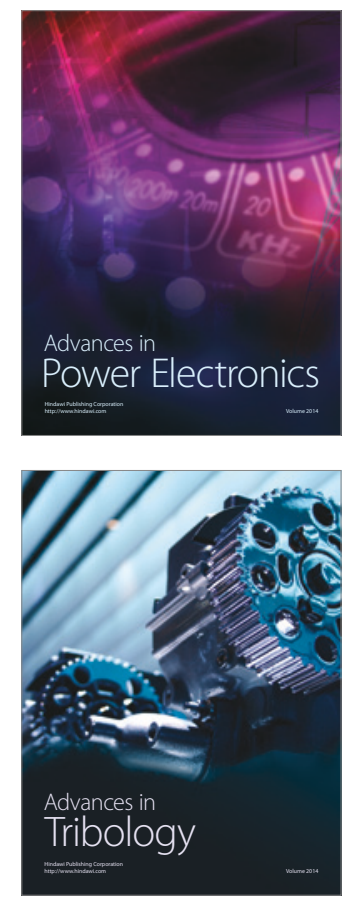
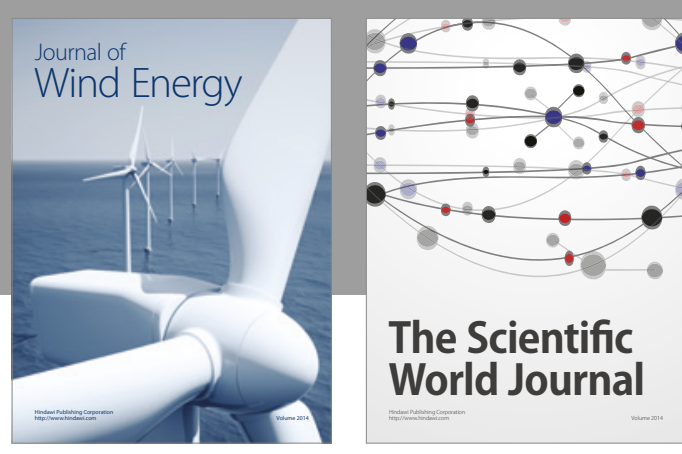

The Scientific World Journal
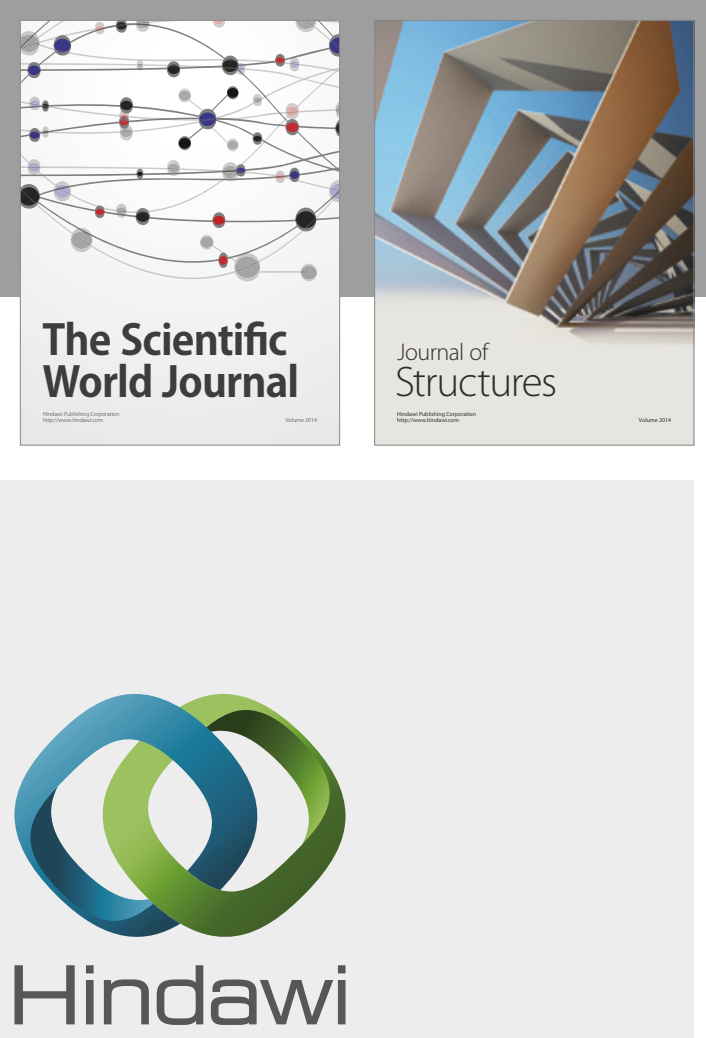

Submit your manuscripts at

https://www.hindawi.com
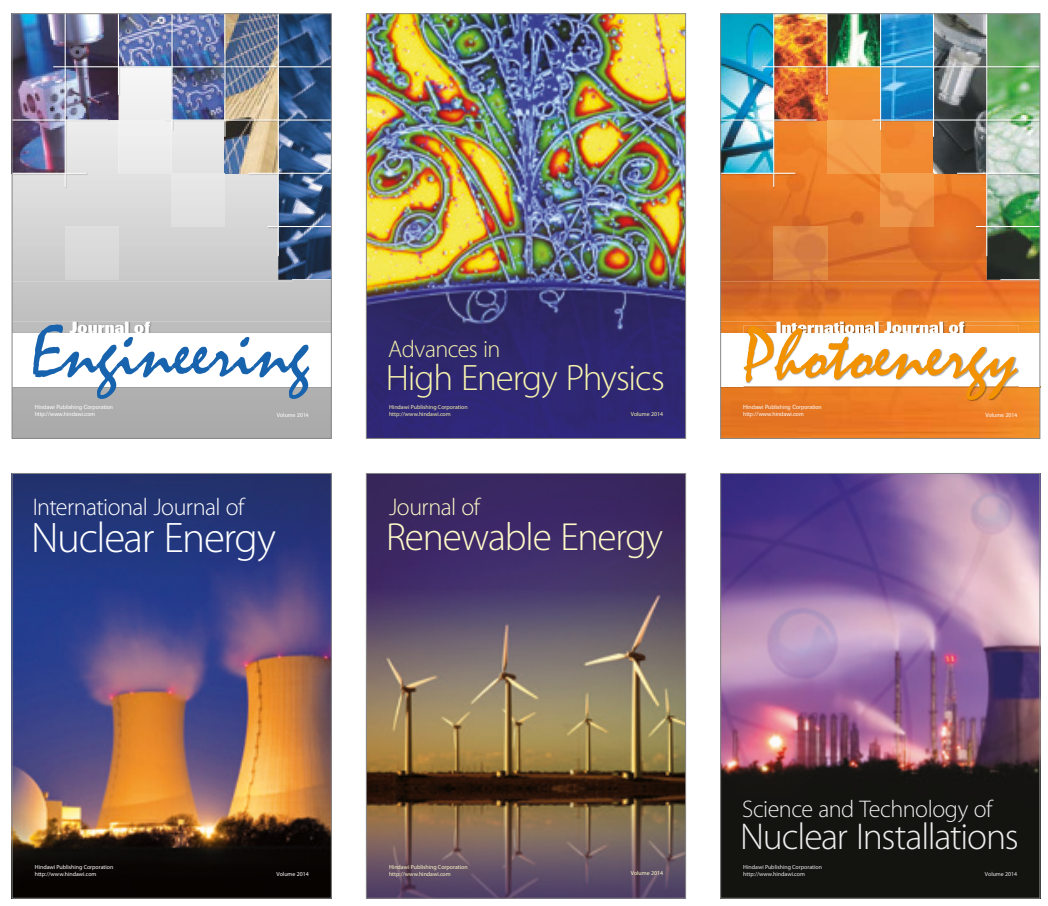

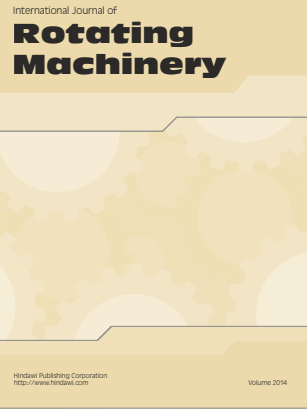

Journal of

Petroleum Engineering

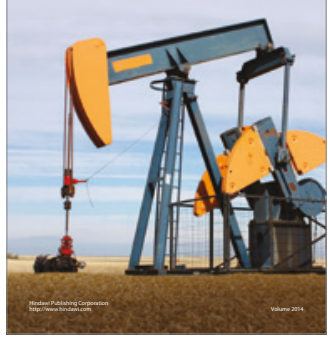

Journal of
Solar Energy
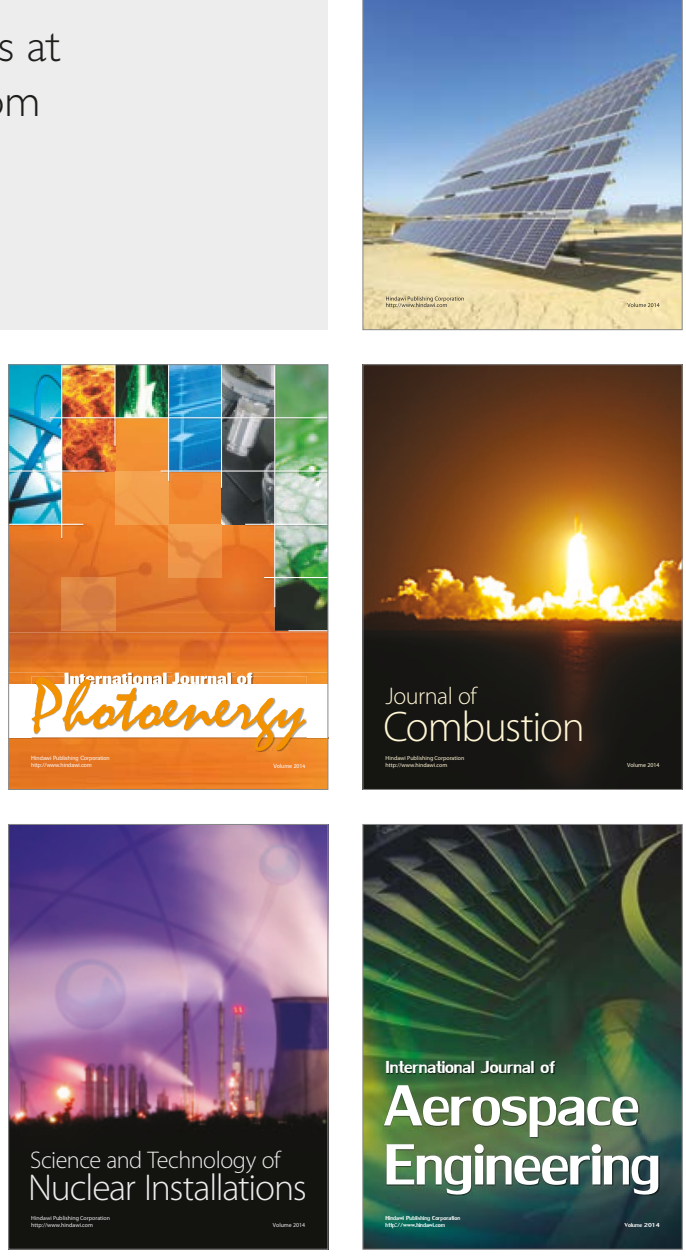